\title{
High gastrin cell activity and low ghrelin cell activity in high-anxiety Wistar Kyoto rats
}

\author{
Elin Kristensson ${ }^{1,2}$, Monika Sundqvist ${ }^{1}$, Rolf Håkanson ${ }^{2}$ and Erik Lindström ${ }^{1}$ \\ ${ }^{1}$ AstraZeneca R\&D, Integrative Pharmacology, Gl Biology, Mölndal, HF449, S-431 83, Sweden \\ ${ }^{2}$ Department of Experimental Medical Science, Lund University, Lund, Sweden \\ (Requests for offprints should be addressed to E Lindström; Email: erik.a.lindstrom@astrazeneca.com)
}

\begin{abstract}
Ghrelin is produced by gastric A-like cells and released in response to food deprivation. Interestingly, psychological stress also raises circulating ghrelin levels. This study compared plasma ghrelin levels in Sprague-Dawley (SPD) rats and high-anxiety Wistar Kyoto (WKY) rats. The two strains were also compared with respect to plasma gastrin, a gastric hormone with a pre- and postprandial release pattern opposite to that of ghrelin, and to the activity of the gastrindependent, histamine-forming ECL cells in the gastric mucosa. The rats were killed after being freely fed or after an over-night fast. The stomachs were weighed and tissue samples were collected for histological and biochemical analysis. Plasma ghrelin and gastrin levels were determined by RIA. While fasted SPD rats had higher plasma ghrelin
\end{abstract}

levels than fasted WKY rats $(P<0 \cdot 001)$, plasma ghrelin did not differ between freely fed rats of the two strains. Gastrin levels were higher in fed WKY rats than in fed SPD rats $(P<$ 0.001). Despite the higher plasma gastrin level, the oxyntic mucosal histidine decarboxylase (HDC) activity (a marker of ECL-cell activity) in fed rats and the mucosal thickness did not differ between the two strains. In a subsequent study, rats were subjected to water-avoidance stress for $60 \mathrm{~min}$, causing plasma gastrin to increase in WKY rats $(P<0.001)$ but not in SPD rats. In conclusion, high-anxiety WKY rats had lower circulating ghrelin and higher gastrin than SPD rats in both the fasted and fed state, while the ECL-cell activity (HDC activity) was only moderately affected.

Journal of Endocrinology (2007) 193, 245-250

\section{Introduction}

Wistar Kyoto (WKY) rats display more anxiety in behavioural tests than other rat strains (Paré 1992, Glowa \& Hansen 1994). By comparison, Sprague-Dawley (SPD) rats represent a lowanxiety strain. Indeed, WKY rats appear to be particularly susceptible to stressful stimuli, manifested as stress-induced gastric ulcer and stress-evoked intestinal mucosal barrier dysfunction (Paré 1990, Saunders et al. 1997). WKY rats also display impaired gastric accommodation and visceral hypersensitivity in response to colorectal distension, perhaps due to high responsiveness to stress (Gunter et al. 2000, Nielsen et al. 2006).

The two peptide hormones gastrin and ghrelin are produced in the stomach (for a review see Walsh 1994, Kojima et al. 1999). While gastrin is produced by G cells in the antrum mucosa, ghrelin is produced by the A-like cells (ghrelin-immunoreactive cells; Date et al. 2000, Dornonville de la Cour et al. 2001, Rindi et al. 2002), located mainly in the oxyntic mucosa together with the histamine-producing ECL cells (Håkanson et al. 1994). ECL cells operate under the control of gastrin (Håkanson et al. 1994), while they are not affected by ghrelin (Dornonville de la Cour et al. 2004). Ghrelin cell-activity does not appear to be controlled by

gastrin (Dornonville de la Cour et al. 2001) while a role of ECL cells in the regulation of ghrelin cells has not been studied to our knowledge. $G$ cells in the antrum are not regulated by ghrelin (Dornonville de la Cour et al. 2004), but are indirectly linked to ECL-cell activity since reduced activity of ECL cells reduces gastric acid secretion, which in turn increases the activity of $\mathrm{G}$ cells (for review, see Håkanson et al. 1994).

Gastrin and ghrelin have opposing secretory patterns; circulating ghrelin levels are high during fasting and decrease in response to food intake (Tschöp et al. 2000, Ariyasu et al. 2001, Dornonville de la Cour et al. 2001), while gastrin levels are low during fasting and high after food intake (for review, see Walsh 1994).

Gastrin stimulates gastric acid secretion by activating the ECL cell-parietal cell axis (for a review see Lindström et al. 2001). In addition, gastrin has tropic effects on the oxyntic mucosa (Håkanson et al. 1986). Ghrelin is thought to contribute to the regulation of food intake (Wren et al. 2000, Asakawa et al. 2001) and utilization of food (Tschöp et al. 2000) but its role in relation to gastrointestinal physiology is unclear. Ghrelin was at first claimed to stimulate gastric acid secretion after both systemic (Masuda et al. 2000) and central administration (Date et al. 2001) to anaesthetized 
rats. In conscious rats, ghrelin was claimed to inhibit acid secretion upon systemic as well as central administration (Sibilia et al. 2002). In contrast, we showed recently that i.v. and s.c. infusion of ghrelin had no effect on acid secretion in conscious rats (gastric fistula rats and pylorus-ligated rats), and that it also had no effects on the different endocrine cells in the stomach (Dornonville de la Cour et al. 2004). However, it seems undisputed that exogenous ghrelin has a prokinetic effect on the stomach in rodents, manifested as an increased rate of gastric emptying (Masuda et al. 2000, Dornonville de la Cour et al. 2004). Interestingly, exogenous ghrelin enhances gastric emptying in patients with idiopathic gastroparesis (Tack et al. 2005). The physiological relevance of these findings is not clear, since genetically induced ghrelin deficiency does not affect gastric emptying (De Smet et al. 2006) and since administration of relatively low, but physiologically active doses of ghrelin had minimal effects on gastric motility in man (Cremonini et al. 2006).

Recent data demonstrate that circulating ghrelin levels are raised in response to psychological stress in both SPD rats and WKY rats (Kristensson et al. 2006), and that ghrelin expression in the oxyntic mucosa is increased in response to stressful stimuli such as tail pinch (Asakawa et al. 2001) and water immersion (Brzozowski et al. 2004). In addition, ghrelin produces anxiety-like behaviour in rats (Carlini et al. 2001, 2004). Interestingly, obestatin, a recently discovered peptide hormone derived from the same precursor as ghrelin, is claimed to produce opposing effects on ingestive behaviour and cause anxiolytic effects in rats (Zhang et al. 2005, Carlini et al. 2007). Since circulating ghrelin is elevated in response to stress, we compared SPD rats and high-anxiety WKY rats with respect to the activity of A-like cells and $G$ cells. We measured plasma ghrelin, which reflects A-like cell activity (Ariyasu et al. 2001, Dornonville de la Cour et al. 2001, Jeon et al. 2004) and plasma gastrin, which reflects G-cell activity. We also examined the activity of the ECL cells in the two strains since these cells are the main target for gastrin (Håkanson et al. 1994). This was done by measuring the activity of oxyntic mucosal histidine decarboxylase (HDC), a well-known marker of ECL-cell activity (Håkanson et al. 1974). Finally, we examined circulating gastrin after $60 \mathrm{~min}$ of water-avoidance stress in order to see whether stress influences not only circulating ghrelin but also gastrin.

\section{Materials and Methods}

\section{Animals}

From Harlan (Horst, The Netherlands), 41 SPD and 42 WKY rats (females) were purchased. WKY rats were 12-14 weeks of age, while SPD rats were 10-12 weeks of age at the start of experiments. They were acclimatized to the animal facility at AstraZeneca for at least 1 week after arrival. They were housed six in each cage $(h=40 \mathrm{~cm}, w=80 \mathrm{~cm}$, $l=60 \mathrm{~cm})$ and kept in a climate-controlled room on a $12 \mathrm{~h}$ light:12 h darkness cycle. Food, water and building material were supplied at all times except during fasting when food and building material were withdrawn. All experiments were approved by the local ethics review committee on animal experiments in Göteborg, Sweden.

\section{Comparison of WKY and SPD rats}

While 18 SPD rats and 18 WKY rats had free access to food, 18 SPD rats and 18 WKY rats were fasted for 16-18 h overnight. All rats were killed at the same time, in the morning between 0800 and 1000 h. Blood samples were collected by exsanguination from the heart for measurement of plasma ghrelin and plasma gastrin concentrations. The stomachs were removed, cut open along the major curvature from the pyloric sphincter to the oesophagus, emptied and weighed. Small tissue samples were collected from the acid-producing part of the stomach (fundus) for assessment of mucosal thickness (for details see Histology). In five fasted and six fed SPD rats and six fasted and fed WKY rats, the oxyntic mucosa was scraped-off the stomach wall and stored at $-20{ }^{\circ} \mathrm{C}$ until the determination of HDC activity (see Biochemical analysis).

\section{Water avoidance stress}

Six WKY rats and five SPD rats (fed ad libitum) were subjected to water avoidance stress (see below), applied as a psychological stressor (Enck et al. 1989). Thirty minutes before exposure to the stress, the rats were anaesthetized with isoflurane (Forene, Abbott Pharmaceutica) and blood was drawn from the tail and collected in heparinized tubes. The rats were allowed to wake up before being placed on a $9.5 \mathrm{~cm}$ high platform $(\varnothing=7.9 \mathrm{~cm}$, the platform itself is $1 \mathrm{~cm}$ high) in a transparent cage $(h=37 \mathrm{~cm}, w=23 \mathrm{~cm}, l=38 \mathrm{~cm})$, containing water. The water had a temperature of $18 \pm$ $1{ }^{\circ} \mathrm{C}$ and reached the lower edge of the platform. All experiments were performed between 0800 and $1000 \mathrm{~h}$. The rats were kept in the cages for $1 \mathrm{~h}$. A second blood sample was drawn from the heart (exsanguination) during renewed isoflurane anaesthesia. Plasma was collected and stored at $-20{ }^{\circ} \mathrm{C}$ until further analysis.

\section{Histology}

Small tissue samples $(2 \times 4 \mathrm{~mm})$ were taken from the central part of the fundus (along the major curvature) and immersed in formalin (10\%) for 2-3 days before transfer to $0 \cdot 01 \mathrm{M}$ PBS and to $70 \%$ ethanol a few days later. The tissue samples were embedded in paraffin, sectioned at $4 \mu \mathrm{m}$ thickness, perpendicular to the mucosal surface, and placed on glass slides. Only transverse sections were examined (entire thickness of mucosa visible). The mucosal thickness was determined after deparaffinizing the sections in xylene and washing in distilled water before staining with hematoxylin/eosin. The mucosal thickness was measured from the base of the gastric glands to 
the mucosal surface, three measurements per section, one section per animal.

\section{Biochemical analysis}

Histidine decarboxylase activity The oxyntic mucosa was weighed and stored at $-20{ }^{\circ} \mathrm{C}$ until homogenization in ice-cold $0 \cdot 1 \mathrm{M}$ sodium phosphate buffer, $\mathrm{pH} 7 \cdot 4$, to a concentration of $100 \mathrm{mg} / \mathrm{ml}$. Aliquots $(80 \mu \mathrm{l})$ of the homogenates were incubated with $\mathrm{L}-\left[1-{ }^{14} \mathrm{C}\right]$ histidine (specific activity $50 \mathrm{mCi} / \mathrm{mmol}$ ), $0.5 \mathrm{mM}$ L-histidine and $0.01 \mathrm{mM}$ pyridoxal-5-phosphate in a total volume of $160 \mu \mathrm{l}$ at $37{ }^{\circ} \mathrm{C}$ for $1 \mathrm{~h}$ as described previously (Larsson et al. 1986). The HDC activity was expressed as pmol ${ }^{14} \mathrm{CO}_{2} / \mathrm{mg}$ per $\mathrm{h}$.

Ghrelin A commercially available RIA kit (Phoenix Pharmaceuticals, Belmont, CA, USA) was used to determine ghrelin according to the manual supplied by the manufacturer. Plasma samples were diluted $1: 4$ or $1: 10$ before the analysis. The antiserum was raised against octanoylated human ghrelin; the tracer was radioiodinated $\left(\mathrm{I}^{125}\right)$ ghrelin28. Rat ghrelin-28 was used as standard. The antiserum recognizes both octanoylated and des-octonoylated ghrelin28. The intra- and inter-assay variation was 3 and $8 \%$ respectively. The concentration of ghrelin in plasma was expressed as picomole equivalents of rat ghrelin-28 per litre.

Gastrin Plasma was analyzed for gastrin by RIA as described earlier using rat gastrin-17 (Research Plus, South Plainfield, NJ, USA) as standard. The antiserum (no. 2604, a kind gift from Professor J F Rehfeld, Rigshospitalet, Copenhagen, Denmark) was raised against the 2-17 fragment of human gastrin-17 and is specific for the bioactive C-terminus. It binds gastrin-34 and gastrin-17 with the same potency. The intra- and inter-assay variation was 7 and $8 \%$ respectively. The gastrin concentration was expressed as picomole rat gastrin17 equivalents per litre plasma.

\section{Statistical analysis}

Statistical analysis was performed using Student's unpaired $t$-test followed by corrections for multiple comparisons using Bonferroni. A $P$ value $<0.05$ was considered statistically significant. All results are expressed as means \pm s.E.M.; $n$ reflects the number of individual rats.

\section{Results}

\section{General features of SPD rats and WKY rats}

The WKY rats in the current study were slightly older than the SPD rats (Table 1). Nonetheless, the WKY rats weighed less $(P<0 \cdot 01)$, as did their stomachs $(P<0 \cdot 001)$. Oxyntic mucosal thickness did not differ between the two strains (Table 1).
Table 1 Comparison between Sprague-Dawley (SPD) and Wistar Kyoto (WKY) rats with respect to age, body weight, stomach weight and oxyntic mucosa thickness

\begin{tabular}{|c|c|c|c|}
\hline & SPD & WKY & $n$ \\
\hline \multicolumn{4}{|l|}{ Parameter } \\
\hline Age (weeks) & $10-12$ & $12-14$ & 2 \\
\hline Body weight (g) & $213+3$ & $199+3 *$ & 2 \\
\hline Stomach weight (g) & $1 \cdot 34 \pm 0.03$ & $1 \cdot 04 \pm 0.02^{+}$ & 2 \\
\hline $\begin{array}{l}\text { Stomach weight/body } \\
\text { weight }(\%)\end{array}$ & $0 \cdot 63 \pm 0 \cdot 01$ & $0 \cdot 52 \pm 0 \cdot 01^{+}$ & 2 \\
\hline $\begin{array}{l}\text { Oxyntic mucosal thickness } \\
(\mu \mathrm{m})\end{array}$ & $581 \pm 24$ & $560 \pm 18$ & 1 \\
\hline
\end{tabular}

Age, body weight and gastric parameters are given for 24 rats of each strain. Additional rats were used for stress experiments. $* P<0 \cdot 01,{ }^{t} P<0 \cdot 001$.

\section{Ghrelin-cell activity}

The circulating ghrelin concentration in fasted SPD rats was more than twice that of the fed controls $(P<0 \cdot 001$, Fig. 1A). In WKY rats, fasting increased circulating ghrelin by only $40 \%(P<0 \cdot 01)$. Fasted SPD rats had much higher ghrelin levels than fasted WKY rats $(P<0 \cdot 001)$, and fed SPD rats tended to have higher ghrelin levels than fed WKY rats (by $20 \%$ ), but this difference was not statistically significant.

\section{Gastrin-cell activity}

As expected, circulating gastrin levels were high in fed rats and low after an overnight fast in both strains of rats $(P<0 \cdot 001$, Fig. 1B). However, the gastrin levels were twofold higher $(P<0 \cdot 001)$ in fed WKY rats than in fed SPD rats and almost threefold higher in fasted WKY rats than in fasted SPD rats, albeit the latter difference was not statistically significant $(P=0 \cdot 06)$.

\section{ECL-cell activity}

As expected, the oxyntic mucosal HDC activity was higher in fed than in fasted rats $(P<0 \cdot 001$, see also Håkanson et al. 1994; Fig. 1C). WKY rats had higher HDC activity than SPD rats in the fasted state $(P<0 \cdot 001)$ and tended to have higher activity in the fed state.

\section{Effects of psychological stress on gastrin levels}

In accordance with the results shown in Fig. 1B, gastrin levels were higher in fed WKY rats than in fed SPD rats $(P<0 \cdot 001$, Table 2). While water-avoidance stress failed to affect circulating gastrin in the SPD rats, it raised it in the WKY rats $(P<0 \cdot 001)$.

\section{Discussion}

The current study demonstrates that high-anxiety WKY rats display high G-cell activity and low A-like (ghrelin) cell activity in comparison to SPD rats, which are classified as a low-anxiety 

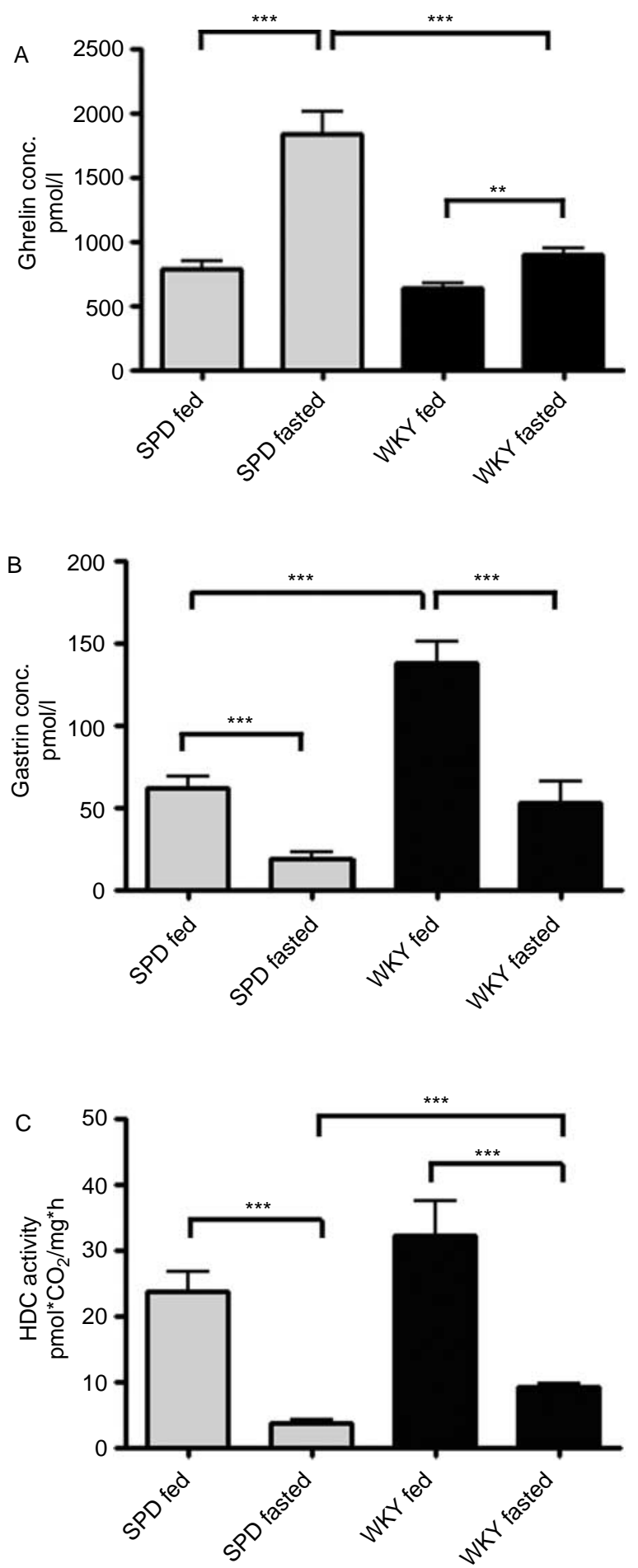

Figure 1 (A) Plasma ghrelin $(n=12-18)$, (B) plasma gastrin $(n=10)$ and $(\mathrm{C})$ oxyntic mucosal histidine decarboxylase activity $(n=5-6)$ in fed and fasted SPD and WKY rats. Statistical analysis was performed using Student's $t$-test followed by correction for multiple comparisons. Mean \pm S.E.M. ${ }^{* *} P<0 \cdot 01,{ }^{* * *} P<0 \cdot 001$.
Table 2 Effects of water-avoidance stress (WAS) on plasma gastrin levels in fed Sprague-Dawley (SPD) and fed Wistar Kyoto (WKY) rats

\section{Plasma gastrin before WAS (pmol/l)}

Strain

SPD

WKY

\author{
$87 \cdot 5 \pm 8 \cdot 2$ \\ $156 \cdot 1 \pm 5 \cdot 9^{+}$
}

Plasma gastrin after

$83 \cdot 3 \pm 16 \cdot 2$
$225 \cdot 2 \pm 8 \cdot 2^{\ddagger, *}$ WAS (pmol/l)

\section{n}

*Plasma gastrin levels in WKY rats after WAS were significantly $(P<0 \cdot 001)$ higher than in SPD rats after WAS. ${ }^{+}$Plasma gastrin levels in WKY rats were significantly $(P<0 \cdot 001)$ higher than in SPD rats. ${ }^{\ddagger}$ Plasma gastrin levels in WKY rats after WAS were significantly $(P<0 \cdot 001)$ higher than before WAS.

strain. The activity of a third gastric endocrine cell type, the ECL cells, is reflected in the HDC activity; it was moderately increased in fasted WKY rats compared with SPD rats.

Circulating ghrelin levels are known to increase upon food withdrawal (Tschöp et al. 2000, Ariyasu et al. 2001, Dornonville de la Cour et al. 2001). Metabolic stimuli (or the lack of such stimuli) seem to be paramount in the regulation of ghrelin release (Qader et al. 2005, Dornonville de la Cour et al. 2006). We have recently demonstrated that water-avoidance stress increases ghrelin levels in both SPD and WKY rats (Kristensson et al. 2006) and recent reports indicate that local microinfusion of adrenaline/noradrenaline into the gastric submucosa (Dornonville de la Cour et al. 2007) and direct stimulation of the sympathetic nervous system (Mundinger et al. 2006) stimulates ghrelin secretion. Thus, A-like cells may release ghrelin also in response to stimuli other than those associated with reduced nutritional status. Previously, fed WKY rats were observed to have 25\% lower plasma ghrelin levels than the SPD rats although this difference was not statistically significant (Kristensson et al. 2006). Also the results of the present study suggest that fed WKY rats have somewhat lower plasma ghrelin levels than SPD rats (20\% lower, not statistically significant). However, dramatic differences between the strains were seen after an overnight fast in that ghrelin increased more than twofold in SPD rats but only 40\% in WKY rats. Our previous study revealed that although circulating ghrelin increased significantly in WKY rats in response to stress, the magnitude of the increase $(40 \%)$ was lower than the increase seen in SPD rats (85\%; Kristensson et al. 2006). Taken together, the results suggest that A-like cells in SPD rats are more sensitive to fasting-evoked and stress-evoked stimuli than A-like cells in WKY rats. Ghrelin is claimed to protect the stomach against stress-evoked gastric lesions (Brzozowski et al. 2004). Whether the susceptibility of WKY rats to stress-induced gastric ulcers is associated with suppressed activity of the A-like cells remains to be investigated.

Interestingly, circulating gastrin responded somewhat differently in the two strains. Although, as expected, food deprivation reduced plasma gastrin, circulating levels were more than twofold higher in WKY rats than in SPD rats in both the fasted and fed state. Gastrin levels in fed WKY rats 
approached levels reached in SPD rats treated with proton pump inhibitors or histamine $\mathrm{H}_{2}$ receptor antagonists (Hakanson et al. 1995). This observation is consistent with the observation that WKY rats have a lower rate of gastric acid secretion than SPD rats ( $M$ Astin, $M$ Florentzson, $\mathrm{B}$ Holstem and $\mathrm{K}$ Andersson personal communication).

The main targets for gastrin are to be found in the oxyntic mucosa, where gastrin stimulates ECL-cell activity and exerts trophic effects (Håkanson \& Sundler 1990). Surprisingly, given the high levels of circulating gastrin in WKY rats, the thickness of the oxyntic mucosa did not differ between the two strains. The activity of the ECL cells, reflected in the oxyntic mucosal HDC activity, is controlled by circulating gastrin (Håkanson et al. 1974). Although not statistically significant, the HDC activity tended to be lower in fed SPD rats than in fed WKY rats, suggesting that perhaps additional factors are required for gastrin to exert maximal effects in the oxyntic mucosa and that these factors may be lacking in WKY rats. Gastrin acts synergistically with the vagus in the trophic control of the rat oxyntic mucosa, and the ECL cells represent an important target for both gastrin and the vagus (Axelson et al. 1988, Norlén et al. 2005) indicating that they most likely also operate under nervous control.

Interestingly, we could show that the relatively high plasma gastrin levels observed in fed WKY rats were increased even further after subjecting the rats to psychological stress, while circulating gastrin remained unchanged in the SPD rats. Conflicting results exist regarding the effects of psychological stress on circulating gastrin levels. Paternico et al. (1994) showed that stressful stimuli (cold pressor test) did not affect circulating gastrin levels in man and Sandin et al. (1998) could not demonstrate an effect of stress on gastrin levels in horses. On the other hand, acoustic stress in dogs was found to enhance feeding-induced release of gastrin (Gue et al. 1989). Thus, in some species, psychological stress seems to be capable of mobilizing gastrin. The results of the present study extend these findings to the WKY rat strain which is considered hyper-responsive to stress.

In conclusion, our data show that G cells in the WKY rats are more active than those in the SPD rats, manifested as higher plasma gastrin levels, regardless of the prandial state, and as increased levels following stress. In contrast, A-like cells in WKY rats appear to be less active than A-like cells in SPD rats, manifested as low ghrelin levels in response to fasting (current study) and stress (Kristensson et al. 2006). Possible functional consequences of these different activity ratios of three of the major gastric endocrine cell types remain to be explored.

\section{Funding}

There is no conflict of interest that would prejudice the impartiality of the paper.

\section{References}

Ariyasu H, Takaya K, Tagami T, Ogawa Y, Hosoda K, Akamizu T, Suda M, Koh T, Natsui K, Toyooka S et al. 2001 Stomach is a major source of circulating ghrelin, and feeding state determines plasma ghrelin-like immunoreactivity levels in humans. Journal of Clinical Endocrinology and Metabolism 86 4753-4758.

Asakawa A, Inui A, Kaga T, Yuzuriha H, Nagata T, Fujimya M, Katsuura G, Makino S, Fujino MA \& Kasuga M 2001 A role of ghrelin in neuroendocrine and behavioral responses to stress in mice. Neuroendocrinology 74 143-147.

Axelson J, Ekelund M, Håkanson R \& Sundler F 1988 Gastrin and the vagus interact in the trophic control of the rat oxyntic mucosa. Regulatory Peptides 22 237-243

Brzozowski TM, Konturek PC, Kwiecien S, Pajdo R, Drozdowicz D, Pawlik M, Konturek SJ, Pawlik WW \& Hahn EG 2004 Gastroprotective effect of central and peripheral ghrelin involves prostaglandin, nitric oxide and the activation of vagal and sensory nerves. Regulatory Peptides 120 39-51.

Carlini VP, Monzon ME, Varas MM, Cragnolinin AB, Schiöth HB, Scimonelli TN \& de Barioglio SR 2001 Ghrelin increases anxiety-like behaviour and memory retention in rats. Biochemical and Biophysical Research Communications 299 739-743.

Carlini VP, Varas MM, Cragnolini AB, Schiöth HB, Scimonelli TN \& de Barioglio SR 2004 Differential role of the hippocampus, amygdala, and dorsal raphe nucleus in regulatuing feeding, memory, and anxiety-like behavioural responses to ghrelin. Biochemical and Biophysical Research Communications 313 635-641.

Carlini VP, Schiöth HB \& deBarioglio SR 2007 Obestatin improves memory performance and causes anxiolytic effects in rats. Biochemical and Biophysical Research Communications 352 907-912.

Cremonini F, Camilleri M, Roque MV, McKinzie S, Burton D, Baxter K \& Zinsmeister AR 2006 Obesity does not increase effects of synthetic ghrelin on human gastric motor functions. Gastroenterology 131 1431-1439.

Date Y, Kojima M, Hosoda H, Sawaguchi A, Mondal MS, Suganuma T, Matsukura S, Kangawa K \& Nakazato M 2000 Ghrelin, a novel growth hormone-releasing acylated peptide, is synthesized in a distinct endocrine cell type in the gastrointestinal tract of rats and humans. Endocrinology 141 4255-4261.

Date Y, Nakazato M, Noboru M, Kojima M, Kangawa K \& Matsukura S 2001 Ghrelin acts in the central nervous system to stimulate gastric acid secretion. Biochemical and Biophysical Research Communications 280 904-907.

De Smet B, Depoortere I, Moechars D, Swennen Q, Moreaux B, Cryns K, Tack J, Buyse J, Coulie B \& Peeters TL 2006 Energy homeostasis and gastric emptying in ghrelin knockout mice. Journal of Pharmacology and Experimental Therapeutics 316 431-439.

Dornonville de la Cour C, Björkqvist M, Sandvik AK, Bakke I, Zhao C, Chen D \& Håkanson R 2001 A-like cells in the rat stomach contain ghrelin and do not operate under gastrin control. Regulatory Peptides 99 141-150.

Dornonville de la Cour C, Lindström E, Norlén P \& Håkanson R 2004 Ghrelin stimulates gastric emptying but is without effect on acid secretion and gastric endocrine cells. Regulatory Peptides 120 23-32.

Dornonville de la Cour C, Norlén P \& Håkanson R 2007 Secretion of ghrelin from rat stomach A-like cells in situ in response to local microinfusion of regulatory peptides and neurotransmitters. Regulatory Peptides. In press.

Enck P, Merlin V, Erckenbrecht JF \& Wienbeck M 1989 Stress effects on gastrointestinal transit in rat. Gut 30 455-459.

Glowa JR \& Hansen CT 1994 Differences in responses to an acoustic startle stimulus among forty-six rat strains. Behavior Genetics 24 79-84.

Gue M, Peeters T, Depoortere I, Vantrappen G \& Bueno L 1989 Stressinduced changes in gastric emptying, postprandial motility, and plasma gut hormone levels in dogs. Gastroenterology 97 1101-1107.

Gunter WD, Shepard JD, Foreman RD, Myers DA \& Meerveld BG 2000 Evidence for visceral hypersensitivity in high-anxiety rats. Physiology and Behavior 69 379-382.

Håkanson R \& Sundler F 1990 Proposed mechanism of induction of gastric carcinoids: the gastrin hypothesis. Journal of Clinical Investigation 20 S65-S71. 
Håkanson R, Kroesen JH, Liedberg G, Oscarsson J, Rehfeld JH \& Stadil F 1974 Correlation between serum gastrin concentration and rat stomach histidine decarboxylase activity. Journal of Physiology 243 483-498.

Håkanson R, Blom H, Carlsson E, Larsson H, Ryberg B \& Sundler F 1986 Hypergastrinemia produces trophic effects in the stomach but not in pancreas and intestines. Regulatory Peptides 13 225-233.

Håkanson R, Chen D \& Sundler F 1994 The ECL cells. In Physiology of the Gastrointestinal Tract, 3 , pp 1171-1184. Ed. LR Johnson. New York: Raven Press.

Håkanson R, Ding X-Q, Norlén P \& Chen D 1995 Circulating pancreastatin is a marker for the enterochromaffin-like cells of the rat stomach. Gastroenterology 108 1445-1452.

Jeon TY, Lee S, Kim HH, Kim YJ, Son HC, Kim DH \& Sim MS 2004 Changes in ghrelin concentration immediately after gastrectomy in patients with early gastric cancer. Journal of Clinical Endocrinology and Metabolism $\mathbf{8 9}$ 5392-5396.

Kojima M, Hosoda H, Date Y, Nakasato M, Matsuo H \& Kangawa K 1999 Ghrelin is a growth-hormone-releasing acylated peptide from stomach. Nature 402 656-660.

Kristensson E, Sundqvist M, Astin M, Kjerling M, Mattsson H, Dornonville de la Cour C, Håkanson R \& Lindström E 2006 Acute psychological stress raises plasma ghrelin in the rat. Regulatory Peptides 134 114-117.

Larsson H, Carlsson E, Mattsson H, Lundell L, Sundler F, Sundell G, Wallmark B, Watanabe T \& Håkanson R 1986 Plasma gastrin and gastric enterochromaffin-like cell activation and proliferation. Studies with omeprazole and ranitidine in intact and antrectomized rats. Gastroenterology 90 391-399.

Lindström E, Chen D, Norlén P, Andersson K \& Håkanson R 2001 Control of gastric acid secretion: the gastrin-ECL cell-parietal cell axis. Comparative Biochemistry and Physiology Part A: Molecular and Integrative Physiology 128 505-514.

Masuda Y, Tanaka T, Inomata N, Ohnuma N, Tanaka S, Itoh Z, Hosoda H, Kojima M \& Kanagawa K 2000 Ghrelin stimulates gastric acid secretion and motility in rats. Biochemical and Biophysical Research Communications 276 905-908.

Mundinger TO, Cummings DE \& Taborsky GJ Jr 2006 Direct stimulation of ghrelin secretion by sympathetic nerves. Endocrinology 147 2893-2901.

Nielsen MA, Bayati A \& Mattsson H 2006 Wistar Kyoto rats have impaired gastric accommodation compared to Sprague-Dawley rats due to increased vagal cholinergic tone. Scandinavian Journal of Gastroenterology 41 773-781.

Norlén P, Ericsson P, Kitano M, Ekelund M \& Håkanson R 2005 The vagus regulates histamine mobilization from rat stomach ECL cells by controlling their sensitivity to gastrin. Journal of Physiology 564 895-905.

Paré WP 1990 Technique and strain comparison in stress ulcer. Annals of the New York Academy of Sciences 597 223-230.
Paré WP 1992 The performance of WKY rats on three tests of emotional behavior. Physiology and Behavior 51 1051-1056.

Paternico A, Stanghellini V, De Giorgio R, Santaguida P, Capelli M, Zannarini L, Morselli Labate AM, Corinaldesi R \& Barbara L 1994 Effects of acute cold pressor test on vagally stimulated gastric acid secretion and circulating levels of human pancreatic polypeptide and gastrin. Digestion $\mathbf{5 5}$ 154-159.

Qader SS, Salehi A, Håkanson R, Lundquist I \& Ekelund M 2005 Long-term infusion of nutrients (total parenteral nutrition) suppresses circulating ghrelin in food-deprived rats. Regulatory Peptides 131 82-88.

Rindi G, Necchi V, Savio A, Torsello A, Zoli M, Locatelli V, Raimondo F, Cocchi D \& Solcia E 2002 Characterisation of gastric ghrelin cells in man and other mammals: studies in adult and fetal tissues. Histochemistry and Cell Biology 117 511-519.

Sandin A, Girma K, Sjöholm B, Lindholm A \& Nilsson G 1998 Effects of differently composed feeds and physical stress on plasma gastrin concentration in horses. Acta Veterinaria Scandinavica 39 265-272.

Saunders PR, Hanssen NPM \& Perdue MH 1997 Cholinergic nerves mediate stress-induced intestinal transport abnormalities in Wistar-Kyoto rats. American Journal of Physiology 273 G486-G490.

Sibilia V, Pagani F, Guidobono F, Locatelli V, Torsello A, Deghenghi R \& Netti C 2002 Evidence for a central inhibitory role of growth hormone secretagogues and ghrelin on gastric acid secretion in conscious rats. Neuroendocrinology 75 92-97.

Tack J, Depoortere I, Bisschops R, Verbeke K, Janssens J \& Peeters T 2005 Influence of ghrelin on gastric emptying and meal-related symptoms in idiopathic gastroparesis. Alimentary Pharmacology and Therapeutics 22 847-853.

Tschöp M, Smile DL \& Heiman ML 2000 Ghrelin induces adiposity in rodents. Nature $\mathbf{4 0 7}$ 908-913.

Walsh JH 1994 Gastrointestinal hormones. In Physiology of the Gastrointestinal Tract, 3 , pp 1-31. Ed. LR Johnson. New York: Raven Press.

Wren AM, Small CJ, Ward HL, Murphy KG, Dakin CL, Taheri S, Kennedy AR, Roberts GH, Morgan DG, Ghatei MA et al. 2000 The novel hypothalamic peptide ghrelin stimulates food intake and growth hormone secretion. Endocrinology 141 4325-4328.

Zhang JV, Ren P-G, Avsian-Kretchmer O, Luo C-W, Rauch R, Klein C \& Hsueh AJW 2005 Obestatin, a peptide encoded by the ghrelin gene, opposes ghrelin's effects on food intake. Science 310 996-999.

\section{Received in final form 26 February 2007 \\ Accepted 7 March 2007 \\ Made available online as an Accepted Preprint 9 March 2007}

